\title{
Rodents as shared indicators for zoonotic parasites of carnivores in urban environments
}

\author{
L. A. REPERANT ${ }^{1} \uparrow$, D. HEGGLIN ${ }^{1}$, I. TANNER ${ }^{1}$, C. FISCHER ${ }^{2}$ and P. DEPLAZES ${ }^{1 *}$ \\ ${ }^{1}$ Institute of Parasitology, University of Zurich, Winterthurerstrasse 266a, CH-8057 Zurich, Switzerland \\ ${ }^{2}$ Department of Ecology and Evolution, University of Lausanne, Bâtiment de Biologie, CH-1015 Lausanne, Switzerland
}

(Received 24 Fuly 2008; revised 11 November 2008; accepted 13 November 2008; first published online 21 fanuary 2009)

\section{S UMMAR Y}

Rodents are shared intermediate or paratenic hosts for Echinococcus multilocularis, Toxocara spp. and Toxoplasma gondii, and may serve as valuable indicators for assessing the occurrence and the level of environmental contamination and infection pressure with free-living stages of these zoonotic parasites. We investigated 658 non-commensal rodents for parasite infections in the canton of Geneva, Switzerland. The prevalence of infection with E. multilocularis was highest in Arvicola terrestris captured in the north-western area $(16 \cdot 5 \%$, CI: $10 \cdot 1 \%-24 \cdot 8 \%)$, possibly reflecting a higher red fox density due to the low incidence of sarcoptic mange in this part of the canton. The exposure rate to Toxocara spp. was highest in the urban area $(13 \cdot 2 \%$, CI : $7 \cdot 9 \%-20 \cdot 3 \%)$, and may account for higher densities of domestic carnivore and red fox definitive hosts within the city. Exposure to $T$. gondii was widespread $(5 \cdot 0 \%$, CI: 3.2-7.4\%), indicating a ubiquitous distribution of infected cat definitive hosts. Interestingly, a widespread distribution of Taenia taeniaeformis, a parasite mainly transmitted by cats, was similarly evidenced in A. terrestris. Distinct spatial patterns for the different zoonotic parasites likely reflected differences in distribution, abundance, and habitat use of the respective definitive hosts. These results highlight the potential value of rodents as shared indicators for these pathogens.

Key words: Arvicola terrestris, Echinococcus multilocularis, rodent, Taenia taeniaeformis, Toxocara, Toxoplasma gondii, urban.

\section{INTRODUCTION}

Anthropogenic environments favour animal species, such as medium-sized generalist carnivores and rodents, which are able to adapt to or exploit anthropogenic resources. Their populations can reach higher densities than in natural environments due to the great abundance of food resources and shelters (McKinney, 2002). For instance, urban red fox populations (Vulpes vulpes) have increased drastically during the last decades and have been reported in major cities of continental Europe (Deplazes et al. 2004), with higher densities than in rural environments (Harris, 1981; Contesse et al. 2003; Hegglin et al. 2007). Similarly, populations of domestic cats and dogs reach higher density in urban than in rural environments (Afonso et al. 2006, Calhoon and Haspel, 1989; Matter and Daniels, 2001). The presence of non-commensal rodents in anthropogenic environments is strongly influenced by the density and degree of fragmentation of the vegetation cover (Dickman, 1987; Dickman and Doncaster, 1987).

\footnotetext{
* Corresponding author: Institute of Parasitology, University of Zurich, Winterthurerstrasse 266a, CH-8057 Zurich, Switzerland. Tel: +41446358 501. Fax: +4144 6358 907. E-mail: deplazesp@access.uzh.ch

$\uparrow$ Present address: Department of Ecology and Evolutionary Biology, Princeton University, Princeton, NJ 08544-1003, USA.
}

Small mammal species richness may be preserved in urban areas provided a system of small $(>0.65 \mathrm{ha})$ patches of habitats with a well-developed layer of ground vegetation is maintained (Dickman, 1987). Such patches might be present in urban and periurban (or residential) areas, e.g., along streams, in natural city parks, gardens and churchyards. For example, non-commensal rodents, including Apodemus sylvaticus, Myodes (formerly Clethrionomys) glareolus, and Microtus agrestis, were widespread and abundant throughout the city of Oxford, UK, (Dickman and Doncaster, 1987). Likewise, Arvicola terrestris were abundant in a city park and in peri-urban areas of the city of Zurich, Switzerland (Stieger et al. 2002).

Red foxes, domestic carnivores (dogs and cats), and non-commensal rodents are definitive, intermediate or paratenic hosts for zoonotic parasites of public health significance, i.e., the cestode Echinococcus multilocularis, the nematodes Toxocara canis and T. cati, and the coccidian Toxoplasma gondii. Arvicolid rodents (notably A. terrestris and Microtus arvalis) are the main intermediate hosts of E. multilocularis in Europe (Eckert and Deplazes, 2004), while both arvicolid and murid rodents and other animal species are suitable paratenic or intermediate hosts for Toxocara spp. and T. gondii, respectively (Hill and Dubey, 2002; Despommier, 2003). In contrast, sexual reproduction of these parasites occurs in more restrictive definitive host ranges. Red 
foxes are the main definitive hosts of E. multilocularis in Europe (Eckert and Deplazes, 2004). Domestic dogs and cats can act as definitive hosts but are not considered important for transmission of the parasite to rodent intermediate hosts because of low prevalence in dogs (Deplazes et al. 2004) or low egg excretion in cats (Kapel et al. 2006). Canids (mainly domestic dogs and red foxes in Europe) and felids (mainly domestic cats in Europe) are the definitive hosts of $T$. canis and T. cati, respectively (Despommier, 2003). Felids (mainly domestic cats in Europe) are the only definitive hosts of $T$. gondii (Hill and Dubey, 2002).

Carnivore definitive hosts are responsible for the contamination of the environment by the parasites' free-living stages, which are infectious for humans, after shedding eggs or oocysts with their faeces. E. multilocularis, T.canis, T. cati, and T.gondii infect different definitive hosts. Therefore, the environmental contamination by infectious free-living stages, and thereafter the infection pressure by these parasites, is likely to differ and depend on the distribution, abundance and habitat use of the respective definitive hosts, notably in urbanized areas. High prevalences of infection with $T$. canis in domestic dogs and red foxes in urban areas (O'Lorcain, 1994; Habluetzel et al. 2003; Reperant et al. 2007), and high prevalences of infection with $E$. multilocularis in red foxes in peri-urban areas (Hofer et al. 2000; Fischer et al. 2005; Robardet et al. 2008) have notably been reported, suggesting high levels of environmental contamination in these environments.

Non-commensal rodent intermediate or paratenic hosts become infected after ingestion of infectious free-living stages of E. multilocularis, Toxocara spp. or $T$.gondii present in the environment. Because they are shared hosts for zoonotic parasites of carnivores and become infected by free-living stages that are also infectious for humans, we investigated the potential use of non-commensal murid and arvicolid rodents as shared indicators for the occurrence and the level of environmental contamination by these parasites. Contrary to measures of environmental contamination based on the detection of eggs or infectious free-living stages in soil or fecal samples, seroprevalence or prevalence of infection in rodents may represent more direct indicators of the level of infection pressure for humans.

MATERIALS AND METHODS

\section{Study area}

The study was carried out in the canton of Geneva, Switzerland. This conurbation is densely populated with 400000 inhabitants living in an area of $240 \mathrm{~km}^{2}$. The study area was subdivided into three zones of increasing level of urbanization according to human density, as described by Fischer et al. (2005).
Rapidly, the categorization of zones was based on a grid of $100 \mathrm{~m}^{2}$ and an adaptive Kernel method was used to smooth the shapes of the three areas. They are subsequently referred to as rural $(51 \%$ of total area; human population of $0-40$ inhabitants per $\left.\mathrm{km}^{2}\right)$, peri-urban $\left(26 \% ; 40-220\right.$ inhabitants per $\left.\mathrm{km}^{2}\right)$ and urban areas $(23 \%$; up to 3790 inhabitants per $\mathrm{km}^{2}$ ). Additionally, two geographical areas were distinguished. The north-western area, located north of the Rhone river, presented a low incidence of sarcoptic mange in the red fox population during the entire study period (C. Fischer, personal communication). The south-eastern area, located south and east of the Rhone river, experienced in contrast a severe epidemic of sarcoptic mange, which affected the red fox population of the westernmost part of the study area since 1997 , and over the entire area, since the beginning of 2003. The red fox population of the westernmost part of the study area decreased from $4 \cdot 6$ to $5 \cdot 6$ individuals per $\mathrm{km}^{2}$ in 1997 to $0 \cdot 5$ to $1 \cdot 3$ individuals in 2001 (C. Fischer, personal communication).

\section{Rodent samples}

Rodents were trapped in 15 trapping sites located in the three urban areas (five sites per area), of which six were located in the north-western and nine in the south-eastern geographical area (Fig. 1). Trapping sites presented both open and covered habitats. Open habitats were characterized by areas of $>300 \mathrm{~m}^{2}$ of short grass (up to $10 \mathrm{~cm}$ high); covered habitats were characterized by the presence of light to dense undergrowth over an area of $>300 \mathrm{~m}^{2}$. Trapping sites were selected on the presence of signs and tracks of targeted rodent species, i.e., earth monticules characteristic of Arvicola terrestris; holes and grass tracks characteristic of Microtus spp.; holes and other signs characteristic of the presence of Myodes glareolus (formely Clethrionomys glareolus), and/or Apodemus spp. The presence of $A$. terrestris and rodent species of covered habitats was detected over the entire study area. In contrast, few sites presented signs of the presence of Microtus spp., suggesting low population densities over the study area.

We trapped 466 Arvicola terrestris and 35 Microtus arvalis in autumn 2003 and spring 2004, using Topcat traps (TOPCAT Gmbh, Wintersingen, $\mathrm{CH}$ ), which are highly selective for A. terrestris and Microtus spp. We trapped 58 Myodes glareolus, and 99 Apodemus flavicollis in autumn 2003, using Longworth traps (Penlon Ltd, Oxon, GB), which are highly selective for rodent species of covered habitats (Table 1). Identification of rodent species was done following Brohmer (1988). Rodents were frozen at $-20{ }^{\circ} \mathrm{C}$ until dissection. Prior to dissection, rodents were measured, weighed and sexed.

Because the $A$. terrestris sample was the most suited for statistical analyses, (sero)prevalences of 

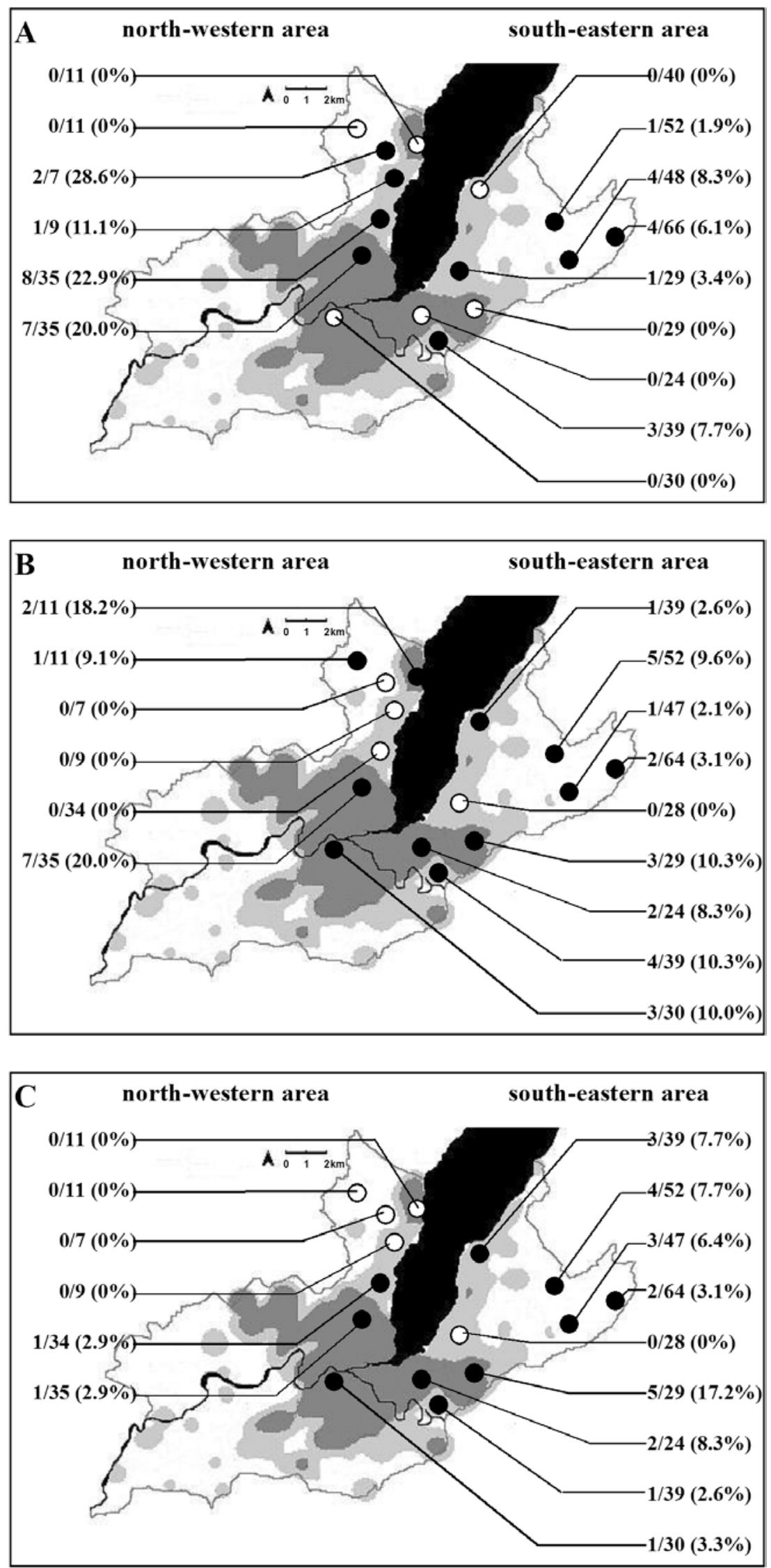

Fig. 1. Prevalence of infection with Echinococcus multilocularis, and seroprevalence of Toxocara spp. and Toxoplasma gondii in Arvicola terrestris from 15 trapping sites in the canton of Geneva, Switzerland. Given are the number of positives/total number of investigated animals and prevalence in parenthesis. Black circles: positive sites; white circles: negative sites for given parasite. Black: lake and rivers; dark grey: urban area; light grey: peri-urban area; white: rural area. (A) Prevalence of infection with E. multilocularis. (B) Seroprevalence of Toxocara spp. (C) Seroprevalence of T. gondii. 
Table 1. Species of rodents captured in the canton of Geneva, Switzerland in autumn 2003 and spring 2004

\begin{tabular}{|c|c|c|c|c|c|c|c|}
\hline & & Total & $\begin{array}{l}\text { Rural } \\
\text { area }\end{array}$ & $\begin{array}{l}\text { Peri- } \\
\text { urban } \\
\text { area }\end{array}$ & $\begin{array}{l}\text { Urban } \\
\text { area }\end{array}$ & $\begin{array}{l}\text { North- } \\
\text { western } \\
\text { area }\end{array}$ & $\begin{array}{l}\text { South- } \\
\text { eastern } \\
\text { area }\end{array}$ \\
\hline \multirow[t]{4}{*}{ Autumn 2003} & Arvicola terrestris & 236 & 99 & 53 & 84 & 73 & 163 \\
\hline & Microtus arvalis & 10 & 10 & 0 & 0 & 7 & 3 \\
\hline & $\begin{array}{l}\text { Myodes (Clethrionomys) } \\
\text { glareolus }\end{array}$ & 58 & 51 & 5 & 2 & 21 & 37 \\
\hline & Apodemus flavicollis & 99 & 44 & 26 & 29 & 47 & 52 \\
\hline \multirow[t]{2}{*}{ Spring 2004} & Arvicola terrestris & 230 & 85 & 100 & 45 & 36 & 194 \\
\hline & Microtus arvalis & 25 & 15 & 4 & 6 & 12 & 13 \\
\hline
\end{tabular}

parasites and their variations were analysed in this species only and for mid- to highly abundant parasites. Two age classes (subadult/adult) were determined based on weight, body length and development of sexual organs. Adult A. terrestris were defined as individuals of $>60 \mathrm{~g}$ and $>120 \mathrm{~mm}$ as described in detail (Stieger et al. 2002).

\section{Parasitological and serological examinations}

Careful examination was performed at the opening of thoracic and peritoneal cavities, and organs, in particular the liver, were attentively examined for lesions. Metacestodes were collected and identified after morphological characteristics and number, shape and length of rostellar hooks. If morphological identification was not possible, liver lesions were squashed and digested using proteinase $\mathrm{K}$, and E. multilocularis infections were diagnosed using PCR as described (Stieger et al. 2002). E. multilocularis cysts containing protoscoleces were cut into small pieces, squashed and washed with PBS through a sieve of $1 \mathrm{~mm}$ mesh size. Flow-through material was investigated under light microscopy and protoscoleces were counted over the entire sample if $<100$ were present. Their numbers were otherwise estimated from three subsamples of $100 \mu 1$.

Transudate was collected from the thoracic cavity and pooled with coagulated blood from the heart, centrifuged for $5 \mathrm{~min}$ at $1000 \mathrm{~g}$ and the supernatant (further referred to as serum) was frozen until use. Enzyme-linked immunosorbent assays (ELISAs) were performed as described (Deplazes et al. 2005) with the following specifications. T. canis excretory/ secretory antigen ( TcE/S-Ag) was prepared following the method described by Speiser and Gottstein (1984), and a commercially available Toxoplasma gondii tachyzoite antigen preparation ( $\mathrm{Tg} \mathrm{T}-\mathrm{Ag}$, Institute Virion Ltd, Rüschlikon, Switzerland) was used. Optimal antigen concentrations were determined by titration experiments in $0.1 \mathrm{M}$ carbonate/ bicarbonate coating buffer ( $\mathrm{pH} 9 \cdot 6)$ containing $0 \cdot 02 \% \mathrm{NaN}_{3}$ (TcE/S-Ag diluted 1:1000, TgT-Ag $4 \mathrm{mg} / \mathrm{ml}$ ). Serum samples were tested in a $1: 200$ dilution in phosphate-buffered saline $(\mathrm{pH} 7 \cdot 2)$ containing $0 \cdot 02 \% \mathrm{NaN}_{3}, 0 \cdot 05 \%$ bovine haemoglobin and $0 \cdot 2 \%(\mathrm{v} / \mathrm{v})$ Tween-20 (PBS-T). As conjugate, goat anti-mouse polyvalent antibodies linked to alkaline phosphatase (Sigma) were used in a dilution of $1: 500$ in PBS-T, and the substrate was a $1 \mathrm{mg} / \mathrm{ml}$ solution of p-nitrophenyl phosphate (Sigma) in 0.05 M carbonate/bicarbonate buffer ( $\mathrm{pH}$ 9.8) containing $1 \mathrm{~mm} \mathrm{MgCl}_{2}$. Reactions were stopped after $10 \mathrm{~min}$ at $+37{ }^{\circ} \mathrm{C}$ by addition of $50 \mu \mathrm{l}$ per well of $3 \mathrm{M} \mathrm{NaOH}$. Absorbance values were read at $405 \mathrm{~nm}\left(\mathrm{OD}_{405}\right)$. Positive control sera of mice experimentally infected with $T$. gondii or $T$. canis and negative control sera of helminth-free mice were included in all test runs.

Specificity of the TcE/S-Ag in ELISA has been reported to be high in mice and no cross-reactions were observed with other experimental larval ascarid infections such as Toxascaris leonina or Ascaris suum (Cuéllar et al. 1995). A previous validation of this antigen in our laboratory using sera of 2 groups of 6 Microtus arvalis experimentally infected with 100 embryonated eggs of $T$. canis and $T$. cati, respectively, resulted in strong antibody reactions (63 days post-inoculation) in both groups, and proved a good sensitivity for both nematode species (data not presented). Validation of the TgT-Ag-ELISA was performed with 22 seropositive and 31 seronegative A. terrestris from another study by performing a T. gondii specific PCR (Müller et al. 1996) after DNA preparation (Qiaamp DNA mini kit, Qiagen, Hilden, Germany) of half of the brain. One of the seronegative samples ( $3 \%$ ) and 14 of the 22 seropositive samples $(64 \%)$ yielded $T$. gondii $\mathrm{PCR}$ positive results. The specificity of the PCR used was determined to be $100 \%$ (Müller et al. 1996), however, its sensitivity for the detection of $T$. gondii-DNA in tissue samples of infected animals was rather low in previous investigations (Wyss et al. 2000). Therefore, PCR confirmation of 14 out of a total of 22 seropositive animals and only 1 PCR positive reaction in 31 seronegative animals confirm the good concordance between the two tests. Cut-off values for both tests were calculated as described (Greiner et al. 1994). 
Table 2. Number of trapping sites and rodents found positive for metacestodes, Toxocara spp. and Toxoplasma gondii in the canton of Geneva, Switzerland

\begin{tabular}{|c|c|c|c|c|c|c|c|c|c|}
\hline & \multicolumn{6}{|c|}{ Parasite identification } & \multicolumn{3}{|c|}{ Serology } \\
\hline & $N$ & $\begin{array}{l}\text { Echinococcus } \\
\text { multilocularis* }\end{array}$ & $\begin{array}{l}\text { Taenia } \\
\text { taeniaeformis }\end{array}$ & $\begin{array}{l}\text { Taenia } \\
\text { crassiceps }\end{array}$ & $\begin{array}{l}\text { Taenia } \\
\text { martis }\end{array}$ & $\begin{array}{l}\text { Mesocestoides } \\
\text { spp. }\end{array}$ & $N^{* * *}$ & $\begin{array}{l}\text { Toxocara } \\
\text { spp. }\end{array}$ & $\begin{array}{l}\text { Toxoplasma } \\
\text { gondii }\end{array}$ \\
\hline Trapping sites & 15 & 9 & 15 & 7 & 2 & 1 & 15 & 12 & 11 \\
\hline Arvicola terrestris & 466 & 31 & 153 & 12 & 0 & 0 & 460 & 31 & 23 \\
\hline Microtus arvalis & 35 & 3 & 6 & 1 & 0 & 1 & 32 & 3 & 1 \\
\hline $\begin{array}{l}\text { Myodes (Clethrionomys) } \\
\text { glareolus }\end{array}$ & 58 & 6 & 3 & 0 & 0 & 0 & 43 & 2 & 0 \\
\hline Apodemus flavicollis & 99 & 0 & 8 & 1 & 2 & 0 & 80 & 4 & 2 \\
\hline
\end{tabular}

* Identified morphologically or by PCR (Stieger et al. 2002).

** Missing samples are due to insufficient quantity of collected serum for $6 \mathrm{~A}$. terrestris, $3 \mathrm{M}$. arvalis, $15 \mathrm{M}$. glareolus, and 19 A. flavicollis.

\section{Statistical analysis}

Statistical analyses were performed with SPSS-PC version 11.5. Factors affecting prevalences were investigated using a backward-stepwise logistic regression procedure based on the likelihood ratio test. Variables included in the initial models were the season (autumn: October-November and spring: April-May), the urbanization area, the geographical area, weight and sex. Results were considered significant when $P<0 \cdot 05$. Exact binomial $95 \%$ confidence intervals (CI) were calculated following (Clopper and Pearson, 1934).

\section{RESULTS}

\section{Larval cestode infections}

Metacestodes of E. multilocularis were morphologically identified in 2 adult $A$. terrestris containing 6850 and 30710 protoscoleces. These two animals were trapped in spring in a peri-urban site located in the north-western geographical area. Additionally, 29 out of 79 A.terrestris, 3 out of $4 M$. arvalis and 6 out of $9 \mathrm{M}$. glareolus, which presented small liver lesions that could not be identified morphologically, were PCR-positive for E. multilocularis. None of 99 A. flavicollis were infected with E. multilocularis (Table 2).

Strobilocerci of $T$. taeniaeformis were morphologically identified in the four rodent species (Table 2). $\mathrm{Up}$ to 11 strobilocerci were found in A.terrestris and up to 6 in A. flavicollis, yet most infected rodents harboured one or few strobilocerci.

Cysticerci of T. crassiceps, located in the pleural cavity or subcutaneously, were found occasionally (Table 2). Infected A.terrestris were captured in one rural, one peri-urban and three urban trapping sites. Two A. flavicollis captured in rural and peri-urban sites were infected in the pleural cavity with two and one specimens of $T$. martis, respectively. Four specimens of Mesocestoides spp. were found in the pleural and peritoneal cavities of $1 M$. arvalis trapped in the urban area (Table 2).

\section{Variations of prevalence of infection with}

E. multilocularis in A. terrestris

A highly significant model was found to explain the variations of prevalence of infection with $E$. multilocularis in $A$. terrestris $\left(\chi^{2}=31 \cdot 2, \quad\right.$ D.F. $=2, \quad P<$ $0 \cdot 0001)$. It included the body weight $(\mathrm{LR}=22 \cdot 9$, $P<0 \cdot 0001)$ and geographical area $(\mathrm{LR}=14 \cdot 0, P<$ $0 \cdot 0001$ ) as significant variables (Table 3 ). Only two subadult $A$. terrestris were found to be infected with E. multilocularis (prevalence of $1 \cdot 3 \%$ ), whereas prevalence in adults was $9 \cdot 2 \%$. The level of urbanization of the habitat had no influence on the prevalence of infection with $E$. multilocularis but $A$. terrestris were more frequently infected in the north-western area (prevalence of $16.5 \%$ ) than in the south-eastern area $(3 \cdot 6 \%)$. Local prevalences in A. terrestris ranged from $11 \cdot 1 \%$ to $28 \cdot 6 \%$ in the north-western area (Fig. 1A).

\section{Variations of prevalence of infection with}

T. taeniaeformis in A. terrestris

Body weight $(\mathrm{LR}=83 \cdot 5, P<0 \cdot 0001)$ and season $(\mathrm{LR}=11 \cdot 5, P=0.001)$ were included in the highly significant model explaining the variations of prevalence of infection with $T$. taeniaeformis $\left(\chi^{2}=85 \cdot 8\right.$, D.F. $=2, P<0.0001$; Table 3$)$. Adult A. terrestris were more frequently infected than subadults (prevalence of $44 \cdot 3 \%$ and $9 \cdot 2 \%$, respectively). Higher T. taeniaeformis prevalence was found in autumn $(36 \cdot 0 \%)$ than in spring $(29 \cdot 6 \%)$, but no spatial variation of prevalence was evidenced. T. taeniaeformis infections were found at all trapping sites throughout the study area with local prevalences in $A$. terrestris ranging from $9 \cdot 1 \%$ to $58 \cdot 3 \%$. 
Table 3. Selected models of the backward-stepwise logistic regression procedure explaining the variations of prevalence or seroprevalence of the 4 main parasite infections diagnosed in Arvicola terrestris from the canton of Geneva, Switzerland

(OR: odd-ratio; CI 95 : $95 \%$ confidence interval.)

\begin{tabular}{|c|c|c|c|c|c|c|c|c|c|}
\hline \multirow[b]{2}{*}{ Variables } & \multirow{2}{*}{$\begin{array}{l}\text { Category/ } \\
\text { Ref. Category }\end{array}$} & \multicolumn{2}{|c|}{$\begin{array}{l}\text { Echinococcus } \\
\text { multilocularis }\end{array}$} & \multicolumn{2}{|c|}{$\begin{array}{l}\text { Taenia } \\
\text { taeniaeformis }\end{array}$} & \multicolumn{2}{|c|}{$\begin{array}{l}\text { Toxocara } \\
\text { spp. }\end{array}$} & \multicolumn{2}{|c|}{$\begin{array}{l}\text { Toxoplasma } \\
\text { gondii }\end{array}$} \\
\hline & & OR & CI 95 & OR & CI 95 & OR & CI 95 & OR & CI 95 \\
\hline Body weight (g.) & & $1 \cdot 040$ & $1 \cdot 017-1 \cdot 063$ & $1 \cdot 052$ & $1 \cdot 038-1 \cdot 065$ & $1 \cdot 040$ & $1 \cdot 018-1 \cdot 062$ & $1 \cdot 032$ & $1 \cdot 010-1 \cdot 055$ \\
\hline Season & Autumn/Spring & - & & $2 \cdot 164$ & $1 \cdot 369-3 \cdot 421$ & - & & - & \\
\hline Sex & Female/Male & - & & - & & - & & - & \\
\hline \multirow{2}{*}{$\begin{array}{l}\text { Urbanization } \\
\text { area }\end{array}$} & Rural/Urban & - & & - & & $0 \cdot 321$ & $0 \cdot 132-0 \cdot 783$ & - & \\
\hline & Peri-urban/Urban & - & & - & & $0 \cdot 214$ & $0.074-0.623$ & - & \\
\hline $\begin{array}{l}\text { Geographical } \\
\text { area }\end{array}$ & $\begin{array}{l}\text { North-western/ } \\
\text { South-eastern }\end{array}$ & $7 \cdot 353$ & $3 \cdot 217-16 \cdot 803$ & - & & - & & - & \\
\hline
\end{tabular}

-, Not significant.

Variations of seroprevalence of Toxocara spp. in A. terrestris

Forty rodents tested positive for antibodies against Toxocara spp., i.e., 31 of 460 A. terrestris, 3 of 32 $M$. arvalis, 2 of $43 \mathrm{M}$. glareolus and 4 of $80 \mathrm{~A}$. flavicollis (Table 2). A highly significant model of logistic regression explained the variations of seroprevalence in A. terrestris $\left(\chi^{2}=24 \cdot 1\right.$, D.F. $=3, P<0 \cdot 0001$; Table 3$)$. It included the body weight $(\mathrm{LR}=15 \cdot 4$, $P<0 \cdot 0001)$ and the urbanization area $(\mathrm{LR}=10 \cdot 7$, $P=0 \cdot 005)$ as significant variables. All sero-positive A. terrestris were adults. Seroprevalence was higher in the urban area $(13.2 \%)$ than in the rural and periurban areas $(4 \cdot 9 \%$ and $3 \cdot 3 \%$, respectively). Seropositive $A$. terrestris were found in all five urban sites, with local prevalences ranging from $8 \cdot 3 \%$ to $20 \cdot 0 \%$ (Fig. 1B).

Variations of seroprevalence of $\mathrm{T}$. gondii in A. terrestris

In total, 26 rodents were found sero-positive for antibodies against $T$. gondii, i.e., 23 of $460 \mathrm{~A}$. terrestris, 1 of $32 M$. arvalis and 2 of 80 A. flavicollis (Table 2). The significant model explaining the variations of seroprevalence of $T$. gondii in $A$. terrestris $\left(\chi^{2}=8 \cdot 8, \quad\right.$ D.F. $\left.=1, P=0.003\right)$ included the body weight as the only significant variable $(\mathrm{LR}=8 \cdot 8$, D.F. $=1, P=0.003$; Table 3$)$. Seroprevalence was $6.4 \%$ in adults and $2 \cdot 1 \%$ in subadults. Infected A. terrestris were trapped in rural, peri-urban and urban sites, with local prevalences ranging from $2.9 \%$ to $17 \cdot 2 \%$ (Fig. $1 \mathrm{C}$ ).

\section{I SCUSS I ON}

Rodent species may serve as valuable shared indicators for assessing the occurrence and the level of environmental contamination and infection pressure with free-living stages of zoonotic parasites of carnivores. However, the variability in the abundance and distribution of the various species of rodents, and in their infection rates makes the sampling design of critical importance. Due to time and logistical constraint, 15 sites were selected over the study area. It allowed for the detection of spatial trends in the occurrence and sero-prevalence of the investigated parasites, with regards to geographical areas and urbanization level of the environment. The selection of the trapping sites in rural, peri-urban and urban areas was based on the detection of the presence of rodent species of both open and covered habitats in order to maximize the trapping success of several rodent species occurring over a wide habitat range. Thus, four species of non-commensal rodents were trapped in the canton of Geneva, and Arvicola terrestris, an arvicolid rodent susceptible to infection with Echinococcus multilocularis, Toxocara spp., and Toxoplasma gondii, was trapped in high numbers throughout the canton, in both rural and urbanized areas. This species therefore appears suitable for surveillance studies of these zoonotic parasites in a wide range of habitats. Few Microtus arvalis were trapped over the entire study area. The rare presence of signs characteristic of Microtus spp. suggested low population densities over the study area. A. terrestris has been shown to be red foxes' main prey in western Switzerland (Weber and Aubry, 1993). It therefore may be the most important intermediate host of E. multilocularis in this region.

A higher prevalence of infection with $E$. multilocularis was found in $A$. terrestris trapped in the north-western area. This may be explained by a significant decrease in red fox density in the southeastern area at the time of the study, caused by an epizootic of sarcoptic mange affecting, since early 2003, the entire area located south of the Rhone river (C. Fischer, personal communication). Sarcoptic mange is fatal in wild carnivores and short-term 
mortality rates may reach up to $90 \%$ in affected red fox populations (Pence and Ueckermann, 2002). Thus, red fox densities in the westernmost part of the study area, which was affected by the epidemic of sarcoptic mange since 1997, decreased by up to 10 -fold. Variations in the level of environmental contamination with eggs of $E$. multilocularis are associated with variations in the density of fox faeces, which is influenced by fox density and social structure (Pleydell et al. 2004). A reduction in the number of red foxes has notably been shown to reduce the level of environmental contamination by eggs of E. multilocularis (Raoul et al. 2003). Interestingly, a cluster of infection with the nematode Capillaria hepatica in A.flavicollis, M.glareolus and A.terrestris has also been reported in the north-western area (Reperant and Deplazes, 2005), and may also be associated with a higher red fox density. $C$. hepatica develops in the hepatic parenchyma of rodents mainly, and carnivore species are believed to amplify its cycle, as infectious eggs are liberated in their faeces upon digestion of infected rodents (Childs et al. 1988).

High prevalences of infection with $E$. multilocularis were found in urbanized areas north of the Rhone River, demonstrating a significant infection pressure in these environments. Prevalences of infection with $E$. multilocularis were similarly found high in red foxes from peri-urban areas of the canton of Geneva (Fischer et al. 2005; Reperant et al. 2007) and in red foxes and arvicolid rodents from periurban areas in Zurich (Hofer et al. 2000 ; Stieger et al. 2002). The risk of infection for humans is thus perceived to be maximal in environments at the interface of rural and urban areas (Deplazes et al. 2004). The permanent presence of $E$. multilocularis in urbanized areas may lead to major changes in the epidemiology of the disease in humans (Vuitton et al. 2003). Importantly, the density of $A$. terrestris has been found to be a risk factor for infection with E. multilocularis in humans (Viel et al. 1999), and the occurrence of this rodent up to urbanized areas may contribute to the establishment of the parasite in cities and residential areas. The presence of suitable habitats for rodent intermediate hosts appears indeed to be primordial in the transmission dynamics of E. multilocularis in Europe and China (Danson et al. 2006). Over the present study area, A. terrestris infected with the parasite were trapped in only 1 out of 5 urban sites, which is in accordance with lower prevalence of infection with $E$. multilocularis in urban red foxes in Geneva (Fischer et al. 2005; Reperant et al. 2007).

High prevalence of infection with $E$. multilocularis was also found in $M$. glareolus, which is an arvicolid rodent occurring preferentially in covered habitats, such as bushes, hedges and woods. Prevalences of infection with E. multilocularis in this species were typically lower in other studies (Loos-Frank and
Zeyhle, 1982; Bonnin et al. 1986; Stieger et al. 2002). Our findings suggest that red foxes may intensively use wooded areas of the canton of Geneva, resulting in a significant environmental contamination with eggs of E. multilocularis. The risk of infection for humans in these areas intensively used for leisure activities may thus be significant.

The seroprevalence of Toxocara spp. in A. terrestris increased significantly with the level of urbanization, suggesting a high infection pressure by these nematodes in urban areas. Soil contamination with Toxocara eggs has been found higher in urban than in rural areas (Mizgajska, 1997, 2001; Giacometti et al. 2000; Dubna et al. 2007). High densities of wild and domestic carnivores within cities, in particular in green areas where establishment of rodent prey populations is possible, are likely to result in high focal levels of environmental contamination in urban areas (Mizgajska, 1997, 2001). High prevalences of infection with $T$. canis in red foxes have notably been reported in the city of Geneva (Reperant et al. 2007). However, no differences in fox prevalence rates were detected between rural, peri-urban, and urban areas, further suggesting that domestic carnivores may contribute to environmental contamination in urban areas. Few studies have investigated the natural exposure of populations of wild rodents to Toxocara spp. by a serological method comparable to that used here, and reported likewise higher seroprevalences in urban or peri-urban rodent populations (Dubinsky et al. 1995; Antolova et al. 2004). Serological surveys of rodents, e.g., A. terrestris, may thus represent another tool for monitoring the environmental contamination and infection pressure by Toxocara spp. up to most urbanized areas.

A ubiquitous occurrence of $T$. gondii and of the cestode Taenia taeniaeformis was found as determined by seroprevalence and prevalence of infection in A. terrestris, respectively. No spatial trend could be detected for these two parasites which appeared widely distributed throughout rural, peri-urban and urban parts of the canton of Geneva. The cestode T. taeniaeformis develops to its patent stage nearly exclusively in the cat whereas foxes or dogs are rarely infected with non-reproductive stages (P. Deplazes, unpublished observations). Patent infections with excretion of $T$. gondii oocysts occur strictly in felids (Hill and Dubey, 2002), and therefore cats only are responsible for environmental contamination with oocysts in the area investigated. These results suggest a ubiquitous spatial distribution of infected domestic cats, up to most urbanized environments. It has been proposed that infection rates of $T$. gondii in cats reflects infection rates in prey, notably rodents (Hill and Dubey, 2002). Because no practical methods for the sensitive detection and isolation of oocysts from environmental samples have yet been implemented (Dumetre and Darde, 2003), seroprevalence of $T$. gondii in rodent intermediate 
hosts may represent a most valuable tool for the monitoring of the level of environmental contamination and infection pressure by this coccidian (Aramini et al. 1999).

We are grateful to the Natural History Museum of Chur, Graubünden for providing the Longworth traps, and to V. Bersot and F. Rohr for their help with trapping. We thank L. Kohler for her help with the laboratory work, and A. Mathis and J.-M. Weber for fruitful discussions. We acknowledge the support of our research activities by the Swiss Federal Office for Education and Science and the European Commission (Project Echinorisk, Contract QLK2-CT-2001-01995/BBW Nr. 00.0586-2) and by the Service des Forêts, de la Protection de la Nature et du Paysage (SFPNP) and the Service Vétérinaire of the canton of Geneva.

\section{REFERENCES}

Afonso, E., Thulliez, P. and Gilot-Fromont, E. (2006). Transmission of Toxoplasma gondii in an urban population of domestic cats (Felis catus). International Fournal for Parasitology 36, 1373-1382.

Antolova, D., Reiterova, K., Miterpakova, M., Stanko, M. and Dubinsky, P. (2004). Circulation of Toxocara spp. in suburban and rural ecosystems in the Slovak Republic. Veterinary Parasitology 126, 317-324.

Aramini, J. J., Stephen, C., Dubey, J. P., Engelstoft, C., Schwantje, H. and Ribble, C. S. (1999). Potential contamination of drinking water with Toxoplasma gondii oocysts. Epidemiology and Infection 122, 305-315.

Bonnin, J. L., Delattre, P., Artois, M., Pascal, M., Aubert, M. F. and Petavy, A. F. (1986). [Intermediate hosts of Echinococcus multilocularis in northeastern France. Description of lesions found in 3 naturally infested rodent species]. Annales de Parasitologie Humaine et Comparée 61, 235-243.

Brohmer, P. (1988). Fauna von Deutschland. Quelle and Meyer Verlag, Heidelberg - Wiesbaden, Germany.

Calhoon, R. E. and Haspel, C. (1989). Urban cat populations compared by season, subhabitat and supplemental feeding. The Fournal of Animal Ecology 58, 321-328.

Childs, J. E., Glass, G. E. and Korch, G. W., Jr. (1988). The comparative epizootiology of Capillaria hepatica (Nematoda) in urban rodents from different habitats of Baltimore, Maryland. Canadian Fournal of Zoology 66, 2769-2775.

Clopper, C. J. and Pearson, E. S. (1934). The use of confidence or fiducial limits illustrated in the case of the binomial. Biometrika 26, 404-413.

Contesse, P., Hegglin, D., Gloor, S., Bontadina, F. and Deplazes, P. (2003). The diet of urban foxes (Vulpes vulpes) and the availability of anthropogenic food in the city of Zürich, Switzerland. Mammalian Biology 69, 81-95.

Cuéllar, C., Fenoy, S. and Guillén, J. L. (1995). Cross-reactions of sera from Toxascaris leonina and Ascaris suum infected mice with Toxocara canis, Toxascaris leonina and Ascaris suum antigens. International Fournal for Parasitology 25, 731-739.

Danson, F. M., Giraudoux, P. and Craig, P. S. (2006). Spatial modelling and ecology of Echinococcus multilocularis transmission in China. Parasitology International 55, S227-S231.

Deplazes, P., Hegglin, D., Gloor, S. and Romig, T. (2004). Wilderness in the city, the urbanization of Echinococcus multilocularis. Trends in Parasitology 20, 77-84.

Deplazes, P., Grimm, F., Sydler, T., Tanner, I. and Kape1, C. M. (2005). Experimental alveolar echinococcosis in pigs, lesion development and serological follow up. Veterinary Parasitology 130, 213-222.

Despommier, D. (2003). Toxocariasis, clinical aspects, epidemiology, medical ecology, and molecular aspects. Clinical Microbiology Reviews 16, 265-272.

Dickman, C. R. (1987). Habitat fragmentation and vertebrate species richness in an urban environment. The Journal of Applied Ecology 24, 337-351.

Dickman, C. R. and Doncaster, C. P. (1987). The ecology of small mammals in urban habitats. I. Populations in a patchy environment. The fournal of Animal Ecology 56, 629-640.

Dubinsky, P., Havasiova-Reiterova, K., Petko, B., Hovorka, I. and Tomasovicova, O. (1995). Role of small mammals in the epidemiology of toxocariasis. Parasitology 110, 187-193.

Dubna, S., Langrova, I., Jankovska, I., Vadlejch, J., Pekar, S., Napravnik, J. and Fechtner, J. (2007). Contamination of soil with Toxocara eggs in urban (Prague) and rural areas in the Czech Republic. Veterinary Parasitology 144, 81-86.

Dumetre, A. and Darde, M. L. (2003). How to detect Toxoplasma gondii oocysts in environmental samples? FEMS Microbiology Reviews 27, 651-661.

Eckert, J. and Deplazes, P. (2004). Biological, epidemiological, and clinical aspects of echinococcosis, a zoonosis of increasing concern. Clinical Microbiology Reviews 17, 107-135.

Fischer, C., Reperant, L. A., Weber, J. M., Hegglin, D. and Deplazes, P. (2005). Echinococcus multlocularis infections of rural, residential and urban foxes (Vulpes vulpes) in the canton of Geneva, Switzerland. Parasite 12, 339-346.

Giacometti, A., Cirioni, O., Fortuna, M., Osimani, P., Antonicelli, L., Del Prete, M. S., Riva, A., D’Errico, M. M., Petrelli, E. and Scalise, G. (2000). Environmental and serological evidence for the presence of toxocariasis in the urban area of Ancona, Italy. European Fournal of Epidemiology 16, 1023-1026.

Greiner, M., Franke, C. R., Bohning, D. and Schlattmann, P. (1994). Construction of an intrinsic cut-off value for the sero-epidemiological study of Trypanosoma evansi infections in a canine population in Brazil: a new approach towards an unbiased estimation of prevalence. Acta Tropica 56, 97-109.

Habluetzel, A., Traldi, G., Ruggieri, S., Attili, A. R., Scuppa, P., Marchetti, R., Menghini, G. and Esposito, F. (2003). An estimation of Toxocara canis prevalence in dogs, environmental egg contamination and risk of human infection in the Marche region of Italy. Veterinary Parasitology 113, 243-252.

Harris, S. (1981). An estimation of the number of foxes (Vulpes vulpes) in the city of Bristol, and some possible factors affecting their distribution. The Fournal of Applied Ecology 18, 455-465. 
Hegglin, D., Bontadina, F., Contesse, P., Gloor, S. and Deplazes, P. (2007). Plasticity of predation behaviour as a putative driving force for parasite life-cycle dynamics, the case of urban foxes and Echinococcus multilocularis tapeworm. Functional Ecology 21, 552-560.

Hill, D. and Dubey, J. P. (2002). Toxoplasma gondii, transmission, diagnosis and prevention. Clinical Microbiology and Infection 8, 634-640.

Hofer, S., Gloor, S., Müller, U., Mathis, A., Hegglin, D. and Deplazes, P. (2000). High prevalence of Echinococcus multilocularis in urban red foxes (Vulpes vulpes) and voles (Arvicola terrestris) in the city of Zürich, Switzerland. Parasitology 120, 135-142.

Kapel, C. M., Torgerson, P. R., Thompson, R. C. A. and Deplazes, P. (2006). Reproductive potential of Echinococcus multilocularis in experimentally infected foxes, dogs, raccoon, dogs and cats. International Fournal for Parasitology 36, 79-86.

Loos-Frank, B. and Zeyhle, E. (1982). The intestinal helminths of the red fox and some other carnivores in southwest Germany. Zeitschrift für Parasitenkunde 67, 99-113

Matter, H. C. and Daniels, T. J. (2001). Dog ecology and population biology. In Dogs, Zoonoses and Public Health (ed. MacPherson, C. N. L., Meslin, F. X. and Wandeler, A. I.), CABI Publishing, Wallingford, Oxon., UK.

McKinney, M. L. (2002). Urbanization, biodiversity, and conservation. BioScience 52, 883-890.

Mizgajska, H. (1997). The role of some environmental factors in the contamination of soil with Toxocara spp. and other geohelminth eggs. Parasitology International 46, 46-72.

Mizgajska, H. (2001). Eggs of Toxocara spp. in the environment and their public health implications. Fournal of Helminthology 75, 147-151.

Müller, N., Zimmermann, V., Hentrich, B. and Gottstein, B. (1996). Diagnosis of Neospora caninum and Toxoplasma gondii infection by PCR and DNA hybridization immunoassay. Fournal of Clinical Microbiology 34, 2850-2852.

O'Lorcain, P. (1994). Epidemiology of Toxocara spp. in stray dogs and cats in Dublin, Ireland. Fournal of Helminthology 68, 331-336.

Pence, D. B. and Ueckermann, E. (2002). Sarcoptic mange in wildlife. Revue Scientifique et Technique de l'Office International des Epizooties 21, 385-398.

Pleydell, D. R., Raoul, F., Tourneux, F., Danson, F. M., Graham, A. J., Craig, P. S. and Giraudoux, P. (2004). Modelling the spatial distribution of
Echinococcus multilocularis infection in foxes. Acta Tropica 91, 253-265.

Raoul, F., Michelat, D., Ordinaire, M., Decote, Y., Aubert, M., Delattre, P., Deplazes, P. and Giraudoux, P. (2003). Echinococcus multilocularis, secondary poisoning of fox population during a vole outbreak reduces environmental contamination in a high endemicity area. International Fournal for Parasitology 33, 945-954.

Reperant, L. A. and Deplazes, P. (2005). Cluster of Capillaria hepatica infections in non-commensal rodents from the canton of Geneva, Switzerland. Parasitology Research 96, 340-342.

Reperant, L. A., Hegglin, D., Fischer, C., Kohler, L., Weber, J. M. and Deplazes, P. (2007). Influence of urbanization on the epidemiology of intestinal helminths of the red fox (Vulpes vulpes) in Geneva, Switzerland. Parasitology Research 101, 605-611.

Robardet, E., Giraudoux, P., Caillot, C., Boue, F., Cliquet, F., Augot, D. and Barrat, J. (2008). Infection of foxes by Echinococcocus multilocularis in urban and suburban areas of Nancy, France: influence of feeding habits and environment. Parasite 15, $77-85$.

Speiser, F. and Gottstein, B. (1984). A collaborative study on larval excretory/secretory antigens of Toxocara canis for the immunodiagnosis of human toxocariasis with ELISA. Acta Tropica 41, 361-372.

Stieger, C., Hegglin, D., Schwarzenbach, G., Mathis, A. and Deplazes, P. (2002). Spatial and temporal aspects of urban transmission of Echinococcus multilocularis. Parasitology 124, 631-640.

Viel, J. F., Giraudoux, P., Abrial, V. and BressonHadni, S. (1999). Water vole (Arvicola terrestris scherman) density as risk factor for human alveolar echinococcosis. American Fournal of Tropical Medicine and Hygiene 61, 559-565.

Vuitton, D. A., Zhou, H., Bresson-Hadni, S., Wang, Q., Piarroux, M., Raoul, F. and Giraudoux, P. (2003). Epidemiology of alveolar echinococcosis with particular reference to China and Europe. Parasitology 127, S87-S107.

Weber, J. M. and Aubry, S. (1993). Predation by foxes, Vulpes vulpes, on the fossorial form of the water vole, Arvicola terrestris scherman, in western Switzerland. Fournal of Zoology, London 229, 553-559.

Wyss, R., Sager, H., Müller, N., Inderbitzin, F., König, M., Audigé, L. and Gottstein, B. (2000). [The occurrence of Toxoplasma gondii and Neospora caninum as regards meat hygiene]. Schweizer Archiv für Tierheilkunde 142, 95-108. 